\title{
The bHLH Gene Hes1 as a Repressor of the Neuronal Commitment of CNS Stem Cells
}

\author{
Yuki Nakamura, ${ }^{1}$ Shin-ichi Sakakibara,, ${ }^{1,2}$ Takaki Miyata, ${ }^{1}$ Masaharu Ogawa, ${ }^{3}$ Takuya Shimazaki, ${ }^{5}$ \\ Samuel Weiss, ${ }^{5}$ Ryoichiro Kageyama, ${ }^{4}$ and Hideyuki Okano ${ }^{1,2}$ \\ ${ }^{1}$ Department of Neuroanatomy, Biomedical Research Center, Osaka University, Suita, Osaka 565-0871, Japan, ${ }^{2}$ Core \\ Research for Evolutional Science and Technology, Japan Science and Technology Corporation, Minato, Tokyo 105-0011, \\ Japan, ${ }^{3}$ Laboratory for Cell Culture Development, Brain Science Institute, The Institute of Physical and Chemical \\ Research, Wako, Saitama 351-0198, Japan, 4Institute for Virus Research, Kyoto University, Kyoto 606-8507, Japan, and \\ ${ }^{5}$ Genes and Development Research Group, University of Calgary Faculty of Medicine, Calgary, Alberta T2N 4N1, Canada
}

Hes1 is one of the basic helix-loop-helix transcription factors that regulate mammalian CNS development, and its loss- and gain-of-function phenotypes indicate that it negatively regulates neuronal differentiation.

Here we report that Hes1-1- mice expressed both early (TuJ1 and $\mathrm{Hu}$ ) and late (MAP2 and Neurofilament) neuronal markers prematurely, and that there were approximately twice the normal number of neurons in the $\mathrm{Hes}^{-/-}$brain during early neural development. However, immunochemical analyses of sections and dissociated cells using neural progenitor markers, including nestin, failed to detect any changes in Hes $1^{-1-}$ progenitor population. Therefore, further characterization of neural progenitor cells that discriminated between multipotent and monopotent cells was performed using two culture methods, low-density culture, and a neurosphere assay. We demonstrate that the self-renewal activity of multipotent progenitor cells was reduced in the Hes1 ${ }^{-1-}$ brain, and that their subsequent commitment to the neuronal lineage was accelerated. The Hes $1^{-1-}$ neuronal progenitor cells were functionally abnormal, in that they divided, on average, only once, and then generated two neurons, (instead of one progenitor cell and one neuron), whereas wild-type progenitor cells divided more. In addition, some Hes $1^{-1-}$ progenitors followed an apoptotic fate. The overproduction of neurons in the early Hes1-/- brains may reflect this premature and immediate generation of neurons as well as a net increase in the number of neuronal progenitor cells.

Taken together, we conclude that Hes1 is important for maintaining the self-renewing ability of progenitors and for repressing the commitment of multipotent progenitor cells to a neuronal fate, which is critical for the correct number of neurons to be produced and for the establishment of normal neuronal function.

Key words: Hes1; basic helix-loop-helix (bHLH) transcription factor; neuronal commitment; multipotent progenitor cell; neurosphere assay; apoptosis
The mammalian CNS is derived from a monolayer of germinal neuroepithelial cells, which is composed of self-renewing multipotent progenitor cells (CNS stem cells) in the ventricular zone (VZ) (Rakic, 1988; Bayer and Altman, 1991; McConnell, 1995; Lillien, 1998). These most immature progenitor cells generate mitotic and lineage-restricted intermediate progenitor cells, e.g., neuronal progenitor cells and glial progenitor cells (Luskin et al., 1988; Mayer-Proschel et al., 1997; Qian et al., 1998; Casarosa et al., 1999; Torii et al., 1999). Postmitotic neurons derived from neural progenitor cells subsequently migrate away from the VZ and mature. Putative multipotent progenitor cells can be isolated using the neurosphere formation assay, and successive neurosphere differentiation assays have been used to show their multipotency in giving rise to both neurons and glia (Reynolds et al., 1992; Vescovi et al., 1993; Reynolds and Weiss, 1996). Using

\footnotetext{
Received Aug. 10, 1999; revised Oct. 4, 1999; accepted Oct. 6, 1999.

This work was supported by grants from the Japanese Ministry of Education, Science, and Technology Corporation. S.W. is an Alberta Heritage Foundation for Medical Research Scientist. We are grateful to Amgen for providing NT-3 and BDNF. We thank Drs. Sally Temple, Masato Nakafuku, Tetsuichiro Saito, and Freda Miller for their valuable comments.

Correspondence should be addressed to Dr. Hideyuki Okano, Department of Neuroanatomy, Biomedical Research Center, Osaka University, Suita, Osaka 5650871, Japan. E-mail: okano@nana.med.osaka-u.ac.jp.

Copyright (C) 1999 Society for Neuroscience 0270-6474/99/200283-11\$15.00/0
}

low-density culture, an in vitro clonal analysis procedure, the developmental potential of single mitotic cells, most of which are neuronal progenitor cells, can be monitored by examining the number and morphology of their daughter cells (Temple, 1989; Sakakibara et al., 1996). In this paper, we apply these two culture systems to gain insight into developmental neurobiology, by investigating the effect of Hes 1 on progenitor cells for which markers have not yet been established.

Regulatory cascades of positive- and negative basic helix-loophelix (bHLH) transcription factors play essential roles in mammalian neurogenesis (Kageyama et al., 1995; Kageyama and Nakanishi, 1997; Lee, 1997). The bHLH genes such as Mash1 and NeuroD (Johnson et al., 1990; Guillemot and Joyner, 1993; Lee et al., 1995), are thought to positively regulate neuronal development at the level of commitment and postmitotic differentiation. Other bHLH genes, like Hes1 (Sasai et al., 1992), negatively regulate the transcription of the positive-bHLH genes. Hes 1 (Akazawa et al., 1992; Sasai et al., 1992; Takebayashi et al., 1994) was originally isolated as a mammalian homolog of hairy and Enhancer of Split, which negatively regulate neurogenesis in Drosophila (Ingham et al., 1985; Klämbt et al., 1989; Nakao and Campos-Ortega, 1996). Persistent expression of Hes1 prevents migration of neural progenitor cells out of the VZ and the expression of neuronal markers (Ishibashi et al., 1994). In con- 
trast, Hes $1^{-1-}$ brains prematurely express neurofilaments (Ishibashi et al., 1995). These results indicate that this gene is required for the negative regulation of neuronal differentiation. On a gross level, the neural folds of Hes $1^{-1-}$ embryos sometimes fail to fuse at embryonic day 8.5 (E8.5), and the cranial region is usually still open at E9.5, although no alterations in dorsoventral patterning are seen. Mutant embryos rarely survive beyond E14.5 (Ishibashi et al., 1995), which has hindered the analysis of the role of Hes1 in CNS development. Because neuronal development consists of a series of processes, including neuronal commitment and postmitotic differentiation, the steps that require Hes 1 action remain to be elucidated.

In this report, detailed in vivo and in vitro analyses indicated that in addition to its effects on postmitotic neuronal differentiation, Hes 1 normally functions to repress the commitment of multipotent progenitor cells to the neuronal lineage, thereby maintaining their self-renewing state (see Fig. 5).

\section{MATERIALS AND METHODS}

\section{Animals}

The Hes $1^{-1-}$ mice were described previously (Ishibashi et al., 1995). Hes $1^{-/-}$mice and their wild-type littermates were used throughout these experiments. Successful matings were identified by the presence of vaginal plugs. Embryonic day 0.5 (E0.5) was defined as noon of the same day that vaginal plugs were observed. Timed pregnant mice were killed with an overdose of diethyl ether, and embryos were obtained by Cesarean section. Embryos were numbered, and their tails were used for genotyping. To extract DNA, tails were digested in proteinase $\mathrm{K}$ buffer containing $0.5 \%$ Nonidet P-40, $20 \mathrm{~mm}$ Tris- $\mathrm{HCl}$, pH 8.4, $50 \mathrm{~mm} \mathrm{KCl}, 2.5$ $\mathrm{mM} \mathrm{MgCl}$, and $2 \mathrm{mg} / \mathrm{ml}$ proteinase $\mathrm{K}$ (Life Technologies, Grand Island, $\mathrm{NY}$ ). To determine the genotypes of embryos from heterozygous intercrosses, we performed PCR with the tail DNA, using primers described previously (Ishibashi et al., 1995). At least three Hes $1^{-1-}$ embryos and three wild-type littermates were used for each experiment. Embryos were examined at E10.5, E12.5, E13.5, and E14.5, but not later, because necrosis of the brains of Hes $1^{-1-}$ embryos starts at approximately E14, and embryos die soon thereafter (Ishibashi et al., 1995).

\section{Immunochemistry}

For cryosectioning, we selected Hes $1^{-1-}$ embryos that did not have an open-brain phenotype (these represented $\sim 30 \%$ of the Hes $1^{-1-}$ embryos) and used their wild-type littermates for anatomical comparison. Embryos were fixed overnight in $4 \%$ paraformaldehyde in $0.1 \mathrm{M} \mathrm{PBS}, \mathrm{pH}$ 7.4 , at $4^{\circ} \mathrm{C}$, cryoprotected in $30 \%$ sucrose in PBS overnight, embedded in O.C.T. compound (Tissue Tek; Miles, Elkhart, IN), and frozen on dry ice. Ten-micrometer-thick cryosections were cut and affixed to 3-aminopropyltriethoxysilane-coated glass slides (Matsunami Glass, Osaka, Japan). For immunocytochemistry, cultured cells were fixed with $4 \%$ paraformaldehyde in PBS for $10 \mathrm{~min}$ at room temperature, then washed three times with PBS.

Standard procedures were used for immunostaining cryosections and cultures, and are described below. The primary antibodies used were: anti-nestin (mouse monoclonal IgM, clone RE6-96, ascitic fluid used at a dilution of 1:1000) (Miyata and Ogawa, 1994); RAT401 Developmental Studies Hybridoma Bank of Iowa University; mouse monoclonal IgG1; 1:200 dilution); anti-proliferating cell nucleus specific antigen (PCNA) (Novocastra; mouse monoclonal IgG; 1:50 dilution); anti-mouse Musashi1 (Msi1) (monoclonal rat IgG; 1:200 dilution) (Kaneko et al., 1999); Ki-67 (Novocastra; polyclonal rabbit antiserum; 1:1000 dilution); anti-microtubule-associated protein 2 (MAP2) (Sigma, St. Louis, MO; mouse monoclonal IgG1; 1:200 dilution); anti-MAP2 (a gift from Dr. Niinobe, Institute of Protein Research, Osaka University; polyclonal rabbit antiserum; 1:2000 dilution) (Niinobe et al., 1988); antineurofilament-M (Chemicon, Temecula, CA; polyclonal rabbit antiserum; 1:300 dilution); TuJ1 (Berkeley Antibody; mouse monoclonal $\mathrm{IgG}_{2 \mathrm{a}} / \kappa ; 1: 200$ dilution); anti-Hu (Oregon University; mouse monoclonal antibody 16A11; 1:200 dilution) (Marusich et al., 1994); anti-glial fibrillary acidic protein (GFAP) (Sigma; mouse monoclonal IgG1; 1:200 dilution); anti-GFAP (Dako, Carpinteria, CA; polyclonal antibody; 1:10 dilution); and anti-O4 (Boehringer Mannheim, Mannheim, Germany; mouse monoclonal IgM; 1:10 dilution). Secondary antibodies conjugated to rhodamine, 7-amino-4-methyl-6-sulfocoumarin-3-acetic acid (AMCA), or dichlorotriazinylaminofluorescein (DTAF) were obtained commercially from Jackson ImmunoResearch (West Grove, PA), Chemicon, or Cappel (Aurora, OH). Hoechst number 33342 (Sigma; used at $10 \mu \mathrm{M}$ ) was used for nuclear staining. Fixed cryosections and cultures were washed three times with PBS, permeabilized with $0.3 \%$ Triton X-100 in PBS for 3 min, washed three times with PBS, and blocked in $1 \%$ skim milk, $10 \%$ donkey serum, and $10 \%$ normal goat serum in PBS for $1 \mathrm{hr}$ at room temperature, followed by incubation with primary antibodies diluted in the same blocking buffer for $1 \mathrm{hr}$ at $37^{\circ} \mathrm{C}$ or overnight at $4^{\circ} \mathrm{C}$. After being washed three times with PBS, they were stained with Hoechst diluted in PBS for $10 \mathrm{~min}$, washed three more times with PBS, then incubated with secondary antibodies diluted in PBS for $1 \mathrm{hr}$ at room temperature. After another three washes with PBS, the samples were mounted on slides and examined with a Zeiss LSM510 confocal imaging system or Zeiss Axioplan2. The cryosections were autoclaved in $0.01 \mathrm{M}$ sodium citrate buffer at $110^{\circ} \mathrm{C}$ for $10 \mathrm{~min}$ before PCNA staining. The proportions of neurons and neuroepithelial cells in telencephalons (Figs. $1 Q, R)$ were calculated based on the MAP2, nestin, and Hoechst staining of high-density cultures described below. The total number of each type of these cells could not be directly compared between wild-type and Hes $1^{-1-}$ mice, because the number of cells in manually dissected brain tissues usually varies greatly. A minimum of 1000 cells in 10 randomly chosen microscopic fields was counted per dish, and the values obtained from at least three animals were averaged and presented as means \pm SEM.

\section{Primary cultures}

Fetuses were removed from the uterus of timed pregnant mice, and placed in Petri dishes containing PBS. Telencephalons were freed from meninges, and the cells were dissociated by mechanical trituration with a fire-narrowed Pasteur pipette. After centrifugation at $1000 \mathrm{rpm}$ for 5 min, cells were resuspended in culture medium, seeded onto dishes specifically prepared for each experiment as described below, and then incubated at $37^{\circ} \mathrm{C}$ in a humidified atmosphere of $5 \% \mathrm{CO}_{2}$. Culture medium was changed every 2 or $3 \mathrm{~d}$. The day the cells were plated was defined as $0 \mathrm{~d}$ in vitro (0 DIV).

High-density culture. Cell suspensions were seeded onto polyethylenimine (Sigma)-coated cover slips in 24-well culture dishes at $5 \times 10^{5}$ cells $/ \mathrm{cm}^{2}$. Cells were incubated until attached for immunostaining to determine the ratios of neurons and neuroepithelial cells (Figs. 1Q,R), or for $4 \mathrm{~d}$, when they were examined for apoptosis (Fig. $4 E$ ), in DMEM/ F-12 (1:1) (Life Technologies) supplemented with $10 \%$ fetal bovine serum (FBS) (JRH Biosciences, Lenexa, KS). For the experiments assessing rescue from apoptosis (Fig. $4 F$ ), cells were incubated for $4 \mathrm{~d}$ in defined medium containing DMEM/F-12 (1:1) supplemented with 15 $\mu \mathrm{g} / \mathrm{ml}$ insulin (Life Technologies), $25 \mu \mathrm{g} / \mathrm{ml}$ transferrin (Life Technologies), $20 \mathrm{~nm}$ progesterone (Sigma), $30 \mathrm{~nm}$ sodium selenite (Sigma), and $60 \mathrm{~nm}$ putrescine (Sigma). Twenty nanograms per milliliter neurotrophic factor 3 (NT-3; Amgen Inc., Thousand Oaks, CA) or $50 \mathrm{ng} / \mathrm{ml}$ brainderived neurotrophic factor (BDNF; Amgen) was added after each medium change at 0,1 , and 3 DIV.

Low-density culture. For clonal analyses of single neuronal progenitor cells (Fig. 3), we used a low-density culture system with a feeder layer of astrocytes, which supports the proliferation and long-term survival of isolated immature cells (Temple, 1989; Sakakibara et al., 1996). Astrocytes harvested from the telencephalons of perinatal ICR mice (Charles River) were maintained for $\sim 3$ weeks until subcultured as follows (Cohen and Wilkin, 1995; Sakakibara et al., 1996). Silicon rubber rings (0.5-mm-thick, $8 \mathrm{~mm}$ inner diameter) were attached to the base of polyethylenimine-coated $35 \mathrm{~mm}$ plastic culture dishes, to create separate culture spaces. Astrocytes were plated outside the ring. The inner space was coated again with fibronectin $(10 \mu \mathrm{g} / \mathrm{ml}$; Sigma), and the telencephalic cells to be tested were seeded at a density of $1 \times 10^{3}$ cells $/ \mathrm{cm}^{2}$. After the cells had attached to the substratum, the rings were removed, and fresh medium was added [DMEM/F-12 (1:1) containing 10\% FBS, $1.7 \mathrm{ng} / \mathrm{ml}$ basic fibroblast growth factor (bFGF; Wako), $3.3 \mathrm{ng} / \mathrm{ml}$ epidermal growth factor (EGF; Wako), $10 \mathrm{ng} / \mathrm{ml} 2.5 \mathrm{~S}$ nerve growth factor (NGF; Wako), $20 \mathrm{~nm}$ progesterone, $30 \mathrm{~nm}$ sodium selenite, $15 \mu \mathrm{g} / \mathrm{ml}$ insulin, and $25 \mu \mathrm{g} / \mathrm{ml}$ transferrin]. We followed the fates of single progenitor cells for $4 \mathrm{~d}$ using a phase-contrast microscope (Olympus, Tokyo, Japan; IX70), identifying these cells from their positions relative to scratches made on the culture dishes with tungsten needles. Images of cells were recorded using a laser videodisc recorder LV R-3000AN (Sony, Tokyo, Japan) or Image Grabber/PCI (Neotech) equipped with a 3 CCD 
color video camera DXC930 (Sony). Long-term low-density culture experiments using wild-type mice demonstrated that $99 \%$ of the proliferating cells generated only neurons (data not shown).

Neurosphere assay. Standard procedures were followed, as described in previous papers (Vescovi et al., 1993; Reynolds and Weiss, 1996; Tropepe et al., 1999). The basic culture medium for the neurosphere assay was composed of DMEM/F-12 (1:1) (Life Technologies) supplemented with $25 \mu \mathrm{g} / \mathrm{ml}$ insulin, $100 \mu \mathrm{g} / \mathrm{ml}$ transferrin, $20 \mathrm{nM}$ progesterone, $60 \mu \mathrm{M}$ putrescine, and $30 \mathrm{~nm}$ sodium selenite. Twenty nanograms per milliliter EGF and $20 \mathrm{ng} / \mathrm{ml} \mathrm{bFGF}$ ( $\mathrm{R}$ and $\mathrm{D}, \mathrm{MN}$ ), for the proliferation medium, and $1 \%$ FBS, for the differentiation medium (EGF and bFGF-free medium), were added to the basic culture medium for the neurosphere assay. It is known that virtually all spheres are clonally derived, when cells are plated at a density $<5 \times 10^{4}$ cells $/ \mathrm{ml}$ (Hulspas et al., 1997).

Primary sphere formation assay. Mechanically dissociated telencephalic cells were plated at $1 \times 10^{5}$ cells $/ 3 \mathrm{ml}$ proliferation medium in each well of a 6 well plate (Corning), with no substrate pretreatment.

Secondary sphere formation assay. Primary spheres were collected and digested with $0.25 \%$ trypsin-EDTA (Life Technologies) for $5 \mathrm{~min}$ at $37^{\circ} \mathrm{C}$. They were then gently triturated with a fire-narrowed Pasteur pipette, spun down at $400 \mathrm{rpm}$ for $3 \mathrm{~min}$, resuspended in proliferation medium, and plated at 500 cells/200 $\mu \mathrm{l}$ in each well of a 96 well ultra-low cluster plate (Corning). The numbers of primary and secondary spheres were counted at 10-14 DIV.

Sphere differentiation assay. Assay slides (hydrophobic coated HT slides; Weaton) with 24 wells, $4 \mathrm{~mm}$ diameter, were coated with polyethylenimine and used for the sphere differentiation assay. Primary spheres were collected and transferred from the proliferation medium to the differentiation medium described above. Single primary spheres in $20 \mu \mathrm{l}$ of differentiation medium were then transferred to each well of a precoated HT slide in a humidified $15 \mathrm{~cm}$ culture dish within a $\mathrm{CO}_{2}$ incubator. The medium was not changed for the remainder of the experiment. These slides were processed $10 \mathrm{~d}$ later for triple-labeled indirect immunocytochemistry to detect three major cell types: neurons, oligodendrocytes, and astrocytes, using TuJ1, anti-O4, and anti-GFAP antibodies, respectively. The phenotype of the progenitor was determined based on the cell types (neuron, astrocyte, and/or oligodendrocyte) that were present in the clone, regardless of the cell number. Approximately 24 spheres per each animal were examined in three independent experiments.

\section{Detection of apoptosis}

To detect apoptosis in vivo, cryosections were stained with the ApopTag Plus in situ apoptosis detection kit (Oncor), according to the manufacturer's instructions, with minor modifications. Before immunodetection of digoxigenin-labeled nicked DNA ends, sections were stained with Hoechst nuclear dye. DTAF-conjugated anti-digoxigenin antibody (Boehringer Mannheim; used at a dilution of 1:500) was used for the immunodetection of apoptotic cells.

\section{Statistical analysis}

The statistical significance of the variations was evaluated using an unpaired two-group $t$ test (either Student's or Welch's $t$ test was used depending on the $F$ test; $p>0.01$ for the Student's $t$ test). Statistically significant differences between mutants and wild-type controls are indicated with an asterisk in the figures.

\section{RESULTS}

There are several developmental stages in neuronal life. Here, we define the most immature self-renewing stem-like cell as the "multipotent progenitor cell" (MP), which gives rise to both neurons and glia; and the unipotent and mitotic cell as the "committed neuronal progenitor cell" (NP), which only generates neurons. "Immature neurons" and "mature neurons", before and after neuronal maturation, respectively, are discriminated by neuronal markers and morphological features. The term "neuronal differentiation" only refers to the postmitotic maturation of neurons in this paper, unless otherwise noted.

\section{Hes1 functions before the expression of early neuronal markers}

To find out at what point the Hes1 mutation started to affect cellular development, the expression patterns of early and late neuronal markers were examined. The late neuronal markers, MAP2 and neurofilament, are primarily expressed in postmigratory mature neurons (Izant and McIntosh, 1980; Debus et al., 1983; Crandall et al., 1986; Johnson and Jope, 1992). More $\mathrm{MAP}^{+}$mature neurons were observed in the Hes $1^{-1-}$ than in the wild-type brain, and MAP2 was prematurely expressed in migrating immature neurons (Fig. $1 A, B$, arrows), consistent with a recent report (Ohtsuka et al., 1999). Neurofilament-M was also prematurely expressed in the Hes $1^{-1-}$ brain (Fig. $1 C, D$ ). The expression of the earliest markers for postmitotic immature neurons, TuJ1 and Hu (Lee et al., 1990; Menezes and Luskin, 1994; Sakakibara et al., 1996; Okano and Darnell, 1997; Wakamatsu and Weston, 1997), begins just after the final cell division. As shown in Figure $1 E-H$, TuJ1 and $\mathrm{Hu}$ seemed to label more newborn neurons in $H e s 1^{-/-}$mice and were expressed earlier in development near the ventricle. This premature expression of early and late neuronal markers was observed both in the telencephalon and mesencephalon of the mutant embryos (Fig. 1 shows the lateral region of the mesencephalon). The number of Hes $1^{-1-}$ neurons in the brains was then quantified by counting immunostained dissociated telencephalic cells (Fig. 1Q). The fraction of $\mathrm{MAP}^{+}$neurons in the Hes $1^{-/-}$telencephalon was approximately twice the number in wild-type (Fig. 1Q) (wildtype: E10.5, $9.0 \pm 1.0 \%$; E12.5, $22.1 \pm 6.3 \%$; E14.5, $15.5 \pm 2.3 \%$; Hes $1^{-1-}:$ E10.5, $22.8 \pm 3.7 \%$; E12.5, $38.3 \pm 4.5 \%$; E14.5, $43.9 \pm$ $2.8 \%,{ }^{*} p<0.01$ in comparison with wild-type at the same developmental stages).

Thus, even at an early stage when immature postmitotic neurons were still migrating, the neurons were increased in the Hes $1^{-1-}$ brain more than in wild-type. These facts suggest that Hes 1 is likely to function in mitotic progenitor cells.

\section{Neural progenitor cells of $\mathrm{Hes1}^{-/-}$mice were indistinguishable from wild-type by immunochemical analyses}

To further investigate whether the overproduction of neurons in the Hes $1^{-1-}$ brain was attributable to an abnormality in the neural progenitor cells, the expression patterns of various markers for neural progenitor cells $(\mathrm{MP}+\mathrm{NP})$ were examined. The antibodies used in this study for the detection of neural progenitor cells were: (1) RAT401 (nestin), an intermediate filament specific to neuroepithelial cells, which correspond to neural progenitor cells (Hockfield and McKay, 1985; Frederiksen and McKay, 1988; Lendahl et al., 1990), (2) anti-PCNA, proliferating cell nucleus specific antigen (Galand and Degraef, 1989), (3) anti-mouse Musashi1 (Msi1), an RNA-binding protein highly enriched in neural progenitor cells (Sakakibara et al., 1996; Sakakibara and Okano, 1997; Kaneko et al., 1999), and (4) Ki-67, an antibody to cell proliferation-associated nuclear antigen (Gerdes et al., 1983; Schlüter et al., 1993; Thomson et al., 1998). Unfortunately, to date, there is no antibody that clearly distinguishes between MPs and NPs.

At E10.5, cells that were positive for these neural progenitor cell markers resided throughout the neural tube from the ventricle to the pia both in Hes $1^{-1-}$ and wild-type mice (Fig. 1I-P). Brains from E12.5 embryos also failed to show differences in the distribution of neural progenitor cells between the two genotypes (data not shown). Because nestin is expressed on neural fibers, 

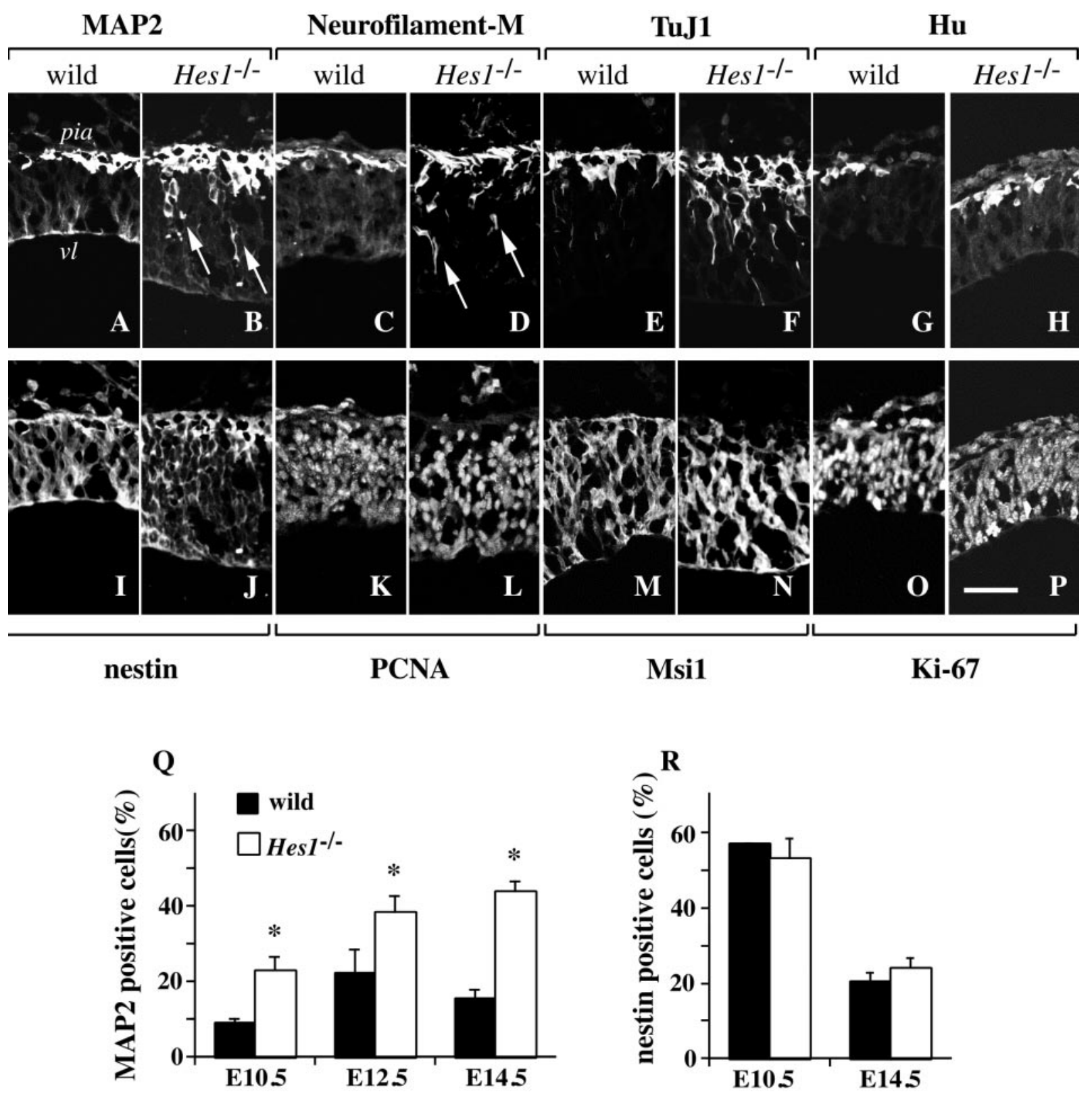

Figure 1. Neurons increase in the Hes $1^{-/-}$brain, without a detectable change in the number and distribution of neural progenitor cells. $A-P$, Immunohistochemical analyses of neurons and neural progenitor cells in the brain. Cryosections of wild-type and Hes $1^{-1-}$ embryos at E10.5 were double-stained with neuronal markers (top row) and neural progenitor cell markers (bottom row): MAP2/RAT401 ( $A$, I; $B, J$ ), neurofilament-M/PCNA $(C, K ; D, L)$, TuJ1/Msi1 $(E, M ; F, N)$, and $\mathrm{Hu} / \mathrm{Ki}-67(G, O ; H, P)$. Panels aligned above and below show identical views of the lateral region of the mesencephalon. The top of each panel corresponds to the pial side. The genotype of the mouse is indicated above each pair of double-stained panels.

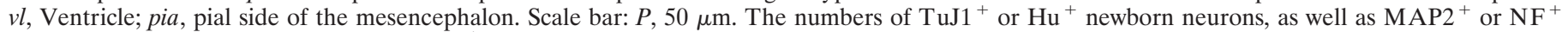
mature neurons were increased in the Hes $1^{-1-}$ brain compared with wild-type. However, the distribution of neural progenitor cells was not significantly changed by the Hes 1 mutation. Furthermore, premature expression of late neuronal markers near the ventricle was observed in Hes $1^{-1-}$ mice $(B, D$, arrows). $Q, R$, Immunocytochemical analyses to quantify the fractions of MAP2 ${ }^{+}$neurons $(Q)$ and nestin ${ }^{+}$neural progenitor cells $(R)$. Wild-type and Hes $1^{-1-}$ brains were dissociated (embryonic stages are indicated below each bar) and stained for MAP2 or nestin, then the ratio of marker-positive cells to total cells was calculated and presented as the mean $\pm \operatorname{SEM}(\%) .{ }^{*} p<0.01$ in comparison to wild-type.) The fraction of Hes $1^{-/-}$neurons was markedly increased, approximately twice that of wild-type, and continued to increase until a later stage (E14.5) (Q). In contrast, there was no statistical difference in the fraction of nestin ${ }^{+}$neural progenitor cells between wild-type and Hes $1^{-1-}$ mice at any developmental stage $(R)$.

instead of in cell bodies (which are readily counted), it remains unclear whether the number of nestin ${ }^{+}$neural progenitor cells was actually unchanged. To quantify the number of neural progenitor cells, telencephalons were dissociated and immunostained. The ratio of Hes $1^{-1-}$ nestin ${ }^{+}$cells to the total number of cells counted was not statistically different from wild-type (Fig. $1 R)$. Taken together, the immunochemical examinations failed to detect any difference in the distribution and number of neural progenitor cells between the Hes $1^{-/-}$and wild-type embryonic brain.

Thus, immunochemical analyses demonstrated that the premature differentiation and overproduction of Hes $1^{-/-}$neurons were not accompanied by any apparent change in the total population of neural progenitor cells (MP + NP). 
A
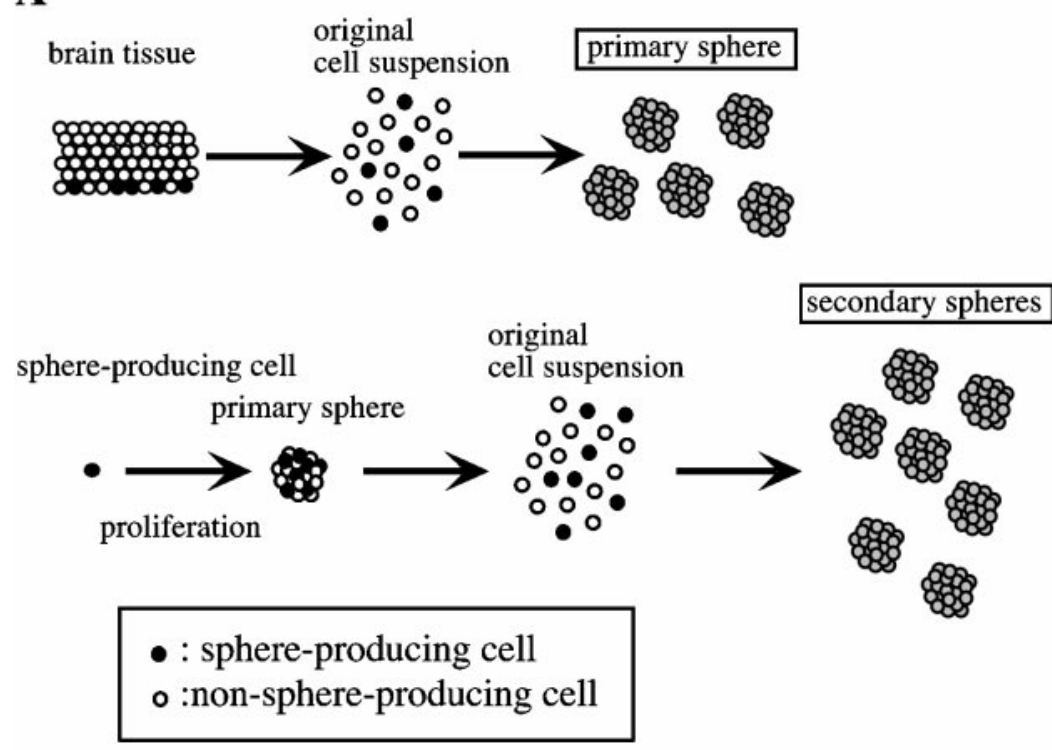

\section{B primary spheres}

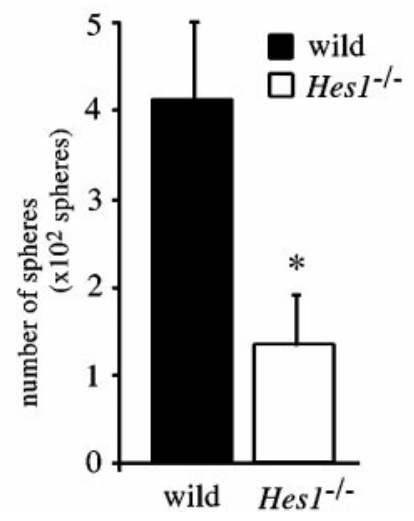

C secondary spheres

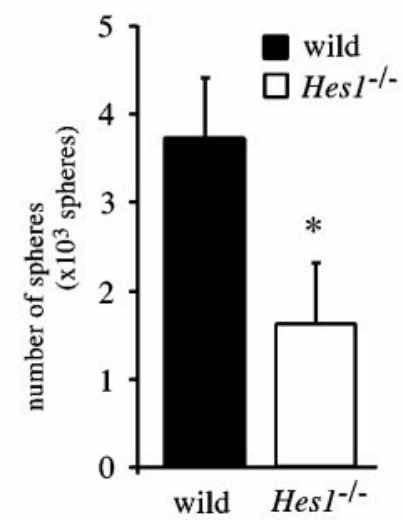

Figure 2. Self-renewing capability of multipotent progenitor cells is lower in Hes. ${ }^{-1-}$ mice (neurosphere formation assay). $A$, Schematic representation of the experimental approaches used to investigate the self-renewing capability of MPs. The number of neurospheres retrospectively indicates the number of sphere-producing cells in the original cell suspension. Because most spheres are clonally derived from self-renewing and multipotent progenitor cells, the number of primary spheres indicates the MP population in the brain, and that of the secondary spheres indicates the MP population in primary spheres. Considering that the primary spheres are the products of the proliferation of the sphere-producing cells, the number of secondary spheres is likely to represent the self-renewing capability of MPs. $B$, Telencephalic cells of E10.5 wild-type and $\mathrm{Hes}^{-1-}$ brains were dissociated and plated at $1 \times 10^{5}$ cells per well of a 6-well plate, and the resultant primary spheres in each well were counted. Note that the number of $\mathrm{Hes}^{-1-}$ primary spheres was smaller, revealing the decreased MPpopulation in the Hes $1^{-1-}$ brain. $C$, These primary spheres were collected, dissociated, and replated at 500 cells per well of a 96-well plate. The number of resultant secondary spheres on each plate was counted (derived from the originally plated $500 \times 96=4.8 \times 10^{4}$ cells). The decreased number of secondary spheres represents the lowered selfrenewal activity of $\mathrm{Hes}^{-1-}$ MPs. All data are presented as the mean \pm SEM of three independent culture experiments. ${ }^{*} p<0.01$ in comparison with the wild-type control.

\section{Self-renewing ability of Hes1 ${ }^{-/-}$MPs was decreased}

Next, to determine whether Hes $1^{-/-}$neural progenitor cells were functionally affected, putative MPs were studied using a neurosphere-formation assay (Reynolds et al., 1992; Reynolds and Weiss, 1996; Tropepe et al., 1999). In the presence of mitogens such as EGF and bFGF, neural progenitor cells proliferate and form clonally derived neurospheres. Most of the sphereproducing progenitor cells are self-renewing and multipotent progenitor cells (Reynolds and Weiss, 1996). In the present study, putative MPs (sphere-producing cells) in the brain were isolated by primary neurosphere formation, and their self-renewing capacity was demonstrated by observing the number of secondary neurospheres formed (Fig. 2A).

Telencephalic cells were dissociated and plated at $1 \times 10^{5}$ cells per well in 6-well plates, cultured for $10 \mathrm{~d}$ in proliferation medium containing EGF and bFGF, and the number of primary spheres per well was counted (Fig. $2 B$ ). The mean number of Hes $1^{-1-}$ primary spheres was one-third of that in wild-type cultures (wildtype, $409 \pm 89$ spheres; $n=15 ;$ Hes $1^{-/-}, 133 \pm 54$ spheres; $n=$ 8 per $1 \times 10^{5}$ cells; $\left.{ }^{*} p<0.01\right)$. To examine whether this decrease in the number of $\mathrm{Hes} 1^{-/-}$primary spheres was merely subse- quent to the accelerated neurogenesis, the number of primary spheres for wild-type brains at E12.5 versus Hes1 ${ }^{-/-}$at E10.5 were compared, because the fraction of MAP2 ${ }^{+}$neurons in the E10.5 Hes ${ }^{-/-}$brain corresponded to that of the E12.5 wild-type brain (Fig. $1 Q)$. We generated $319 \pm 31$ spheres $(n=3$ per $1 \times$ $10^{5}$ cells; ${ }^{*} p<0.01$ ) from E12.5 wild-type telencephalic cells, a number that is still 2.5 times that for Hes1 ${ }^{-/-}$brains at E10.5. Thus, the decrease in the number of primary spheres indicates that there are fewer sphere-producing cells in the Hes ${ }^{-/-}$brain.

In the secondary sphere formation assay, primary spheres were dissociated to form a suspension of single cells, then cultured in the proliferation medium at a density of 500 cells $/ 0.2 \mathrm{ml}$ per well of a 96-well plate, and the secondary spheres that formed were counted 2 weeks later (Fig. $2 C$ ). As schematically shown in Figure $2 A$, the number of secondary spheres corresponds to the number of sphere-producing cells within the primary sphere, which is itself the product of the proliferation of a single sphere-producing cell. Therefore, the number of secondary spheres represents the frequency of self-renewing cell divisions arising from the original sphere-producing cell. The size of the primary neurospheres was not reduced in $\mathrm{Hes}^{-1-}$ mice, indicating that the ability of the 
Table 1. Phenotype composition of clonally derived primary spheres

\begin{tabular}{|c|c|c|c|c|c|c|c|}
\hline & $\mathrm{N}$ & & NG & & & $\mathrm{G}$ & \\
\hline Experimental paradigm & $\mathrm{N}$ & NA & NAO & $\mathrm{NA}+\mathrm{NAO}$ & $\mathrm{AO}$ & A & $\mathrm{AO}+\mathrm{A}$ \\
\hline Wild-type $(n=11)$ & $1.9 \pm 1.4$ & $40.5 \pm 5.1$ & $50.6 \pm 8.1$ & $91.0 \pm 4.0$ & $0.0 \pm 0.0$ & $7.1 \pm 3.6$ & $7.1 \pm 3.6$ \\
\hline Hes1 $1^{-1-}(n=7)$ & $20.8 \pm 5.1^{*}$ & $31.3 \pm 5.7^{*}$ & $39.5 \pm 8.7^{*}$ & $73.2 \pm 2.9^{*}$ & $3.7 \pm 1.9$ & $3.3 \pm 2.2$ & $7.0 \pm 2.9$ \\
\hline
\end{tabular}

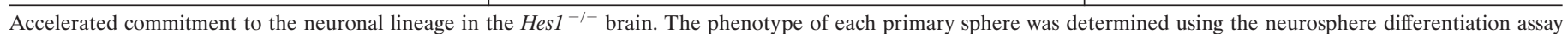

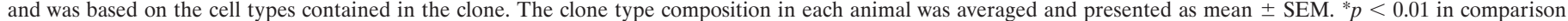

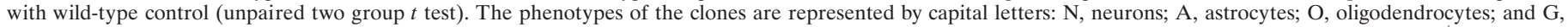

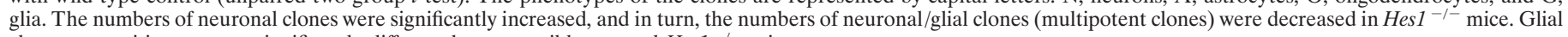
clone composition was not significantly different between wild-type and $\mathrm{Hes} \mathrm{1}^{-1-}$ mice.

sphere-forming cells to proliferate was not affected by the Hes 1 mutation. There were, however, fewer $H e s 1^{-1-}$ secondary spheres than wild-type secondary spheres [wild-type, $3.7 \times 10^{3} \pm$ 0.7 spheres, $n=5$; Hes $1^{-/-}, 1.6 \times 10^{3} \pm 0.7$ spheres, $n=4$, per each plate $\left(500\right.$ cells $\times 96$ wells $=4.8 \times 10^{4}$ original cells $),{ }^{*} p<$ 0.01), indicating that the loss of the Hes 1 gene lowered the self-renewing capability of the sphere-producing cells.

These results indicate that Hes1 functions to keep MPs in a self-renewing state. The next question we asked was whether Hes1 affected the commitment of MPs to a specific cell lineage.

\section{Hes1 represses the commitment of MPs to the neuronal lineage}

We examined whether the Hes 1 mutation affected the multipotency of MPs using a neurosphere differentiation assay. Most neurospheres are derived from multipotent and self-renewing progenitor cells (Reynolds and Weiss, 1996). However, it has also been demonstrated that a certain percentage of neurospheres is derived from committed progenitor cells, which differentiate only into a specific cell type (Reynolds and Weiss, 1996). Here, MPs and NPs, which are indistinguishable by immunochemical analyses, were distinguished retrospectively using a neurosphere differentiation assay. Because one neurosphere is clonally derived from a single progenitor cell, cell types contained within a neurosphere reveal the lineage potency of the original progenitor.

We prepared primary neurospheres derived from E10.5 telencephalons of wild-type and Hes $1^{-1-}$ embryos. These were clonally transferred onto polyethylenimine-coated glass slides for culturing (HT slide), one sphere per well, then were cultured in the absence of EGF and bFGF and in the presence of $1 \%$ fetal bovine serum (differentiation medium) and processed for triplelabeled indirect immunocytochemistry after $10 \mathrm{~d}$ to detect three major cell types. Neurons, oligodendrocytes, and astrocytes were detected using TuJ1, anti-O4, and anti-GFAP antibodies, respectively. The clone type composition of the primary neurospheres is summarized in Table 1. More than $90 \%$ of wild-type neurospheres differentiated into clones containing neurons and glia, and thus were originally multipotential. Less than $2 \%$ of the wild-type spheres were neuronal clones. In contrast, $\sim 20 \%$ of the Hes $1^{-1-}$ neurospheres were neuronal clones, and the fraction of multipotential clones was $73 \%$. The fraction of glial clones was not significantly affected by the Hes 1 mutation (Table 1).

These results directly show that Hes 1 plays a role in repressing the commitment of MPs to the neuronal lineage, but not to the glial lineage, at least in the telencephalon.

\section{Reduced neuronal production by single Hes1 ${ }^{-/-}$NPs}

To characterize the NPs that were overproduced by the accelerated neuronal commitment of MPs in Hes $1^{-1-}$ mice, we took advantage of a low-density culture technique (Sakakibara et al., 1996) as a clonal analysis procedure for demonstrating the devel- opmental potential of NPs (i.e., the number of daughter neurons generated from single NPs). Under our low-density culture conditions, most proliferating cells were NPs, generating only neurons in long-term culture (data not shown). Given this information, the fates of clonally plated proliferating cells (putative NPs) were recorded, and their developmental potentials were retrospectively identified based on the numbers and morphologies of the daughter cells.

Figure 3, $A$ and $B$, shows the representative patterns of neuronal production from NPs that were prepared from E13.5 telencephalons of wild-type $(A)$ and $H e s 1^{-1-}(B)$ mice. As shown in Figure $3 A$, the wild-type NPs (Fig. $3 A a, A b$ ) slowly divided several times, generating a cluster of cells with long processes. In contrast, most Hes $1^{-/-}$NPs (Fig. 3Bd, Bf) divided once, the daughter cells extended short processes within $2 \mathrm{~d}$, and they eventually became apoptotic (Fig. 3Bd, Bf, 3-4 DIV). The relatively short processes of the Hes $1^{-1-}$ neurons did not form network-like connections among neighboring cells, as seen in the wild-type cultures. However, the maturation of the Hes $1^{-1-}$ neurons, which was recognized by the extension of their processes (Fig. $3 B e, B f, 2$ DIV), appeared to be accelerated, consistent with the premature expression of late neuronal markers in vivo (Fig. $1 B-D$, arrows). Some of the Hes $1^{-/-}$neurons also survived beyond the observation period (Fig. 3Be), as did most wild-type neurons.

Figure $3 C$ represents the proliferation pattern of wild-type and NPs Hes $1^{-/-}$, showing the number of daughter cells derived from 100 NPs in the low-density cultures. Although the wild-type NPs showed a continuously increasing number of daughter cells during $4 \mathrm{DIV}, \mathrm{Hes} 1^{-1-}$ NPs increased to twice their original number until 2 DIV (indicating they quickly divided once), then stopped dividing or fell into apoptosis. As a result, the average number of total neurons generated from single NPs was reduced in Hes $1^{-1-}$ mice (Fig. 3D). The number of neurons was reduced irrespective of the developmental stage at which the culture was started, indicating that it did not simply result from an advanced developmental stage (wild-type: E12.5, $3.5 \pm 0.2$ cells; E13.5, $2.9 \pm 0.2$ cells; Hes $1^{-/-}$: E12.5, $2.4 \pm 0.1$ cells; E13.5, $2.3 \pm 0.1$ cells; $\sim 100$ NPs from each of three Hes $1^{-1-}$ and five wild-type mice were observed in three independent experiments; $\left.{ }^{*} p<0.05\right)$. The cell cycle length of Hes $1^{-/-}$NPs was not prolonged, as indicated by the steep rise in the line graph during first $2 \mathrm{~d}$ (Fig. $3 C$ ).

Thus, it seems that the Hes $1^{-1-}$ NPs escaped from their mitotically active state much earlier than wild-type NPs (without reducing their proliferation rate), so the resultant number of their daughter neurons was reduced after $4 \mathrm{~d}$ in culture. The poor survival of $\mathrm{Hes}^{-/-}$cells was the next issue we examined (Fig. 4).

\section{Accelerated apoptosis of the Hes1 ${ }^{-/-}$NPs}

As described above, Hes $1^{-/-}$cultured cells seldom survived beyond 5 DIV, and mutant embryos sometimes exhibited anen- 


\section{A wild}
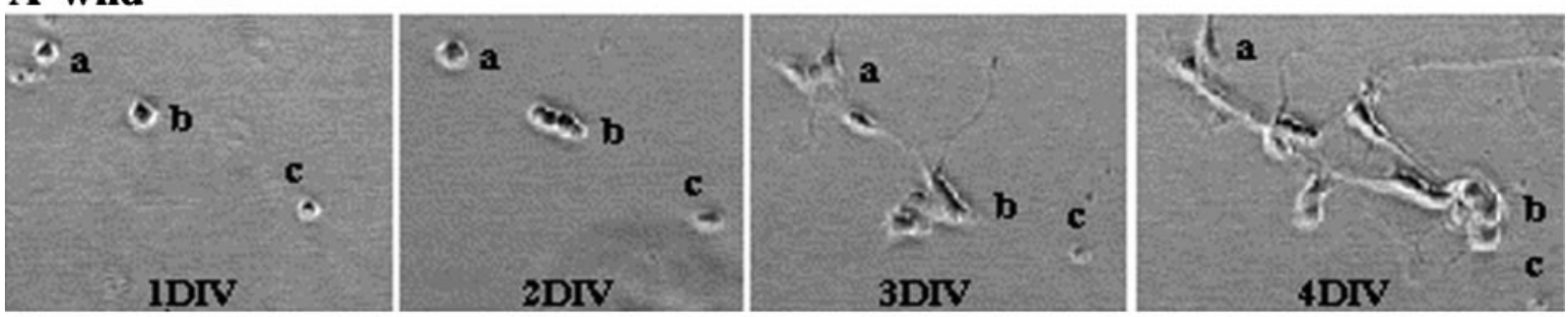

\section{B Hes 1-/-}

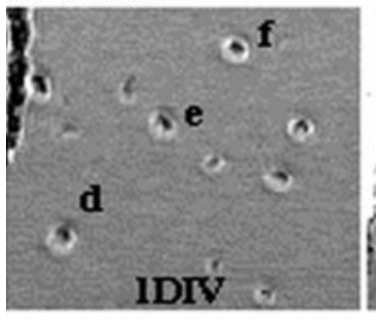

C

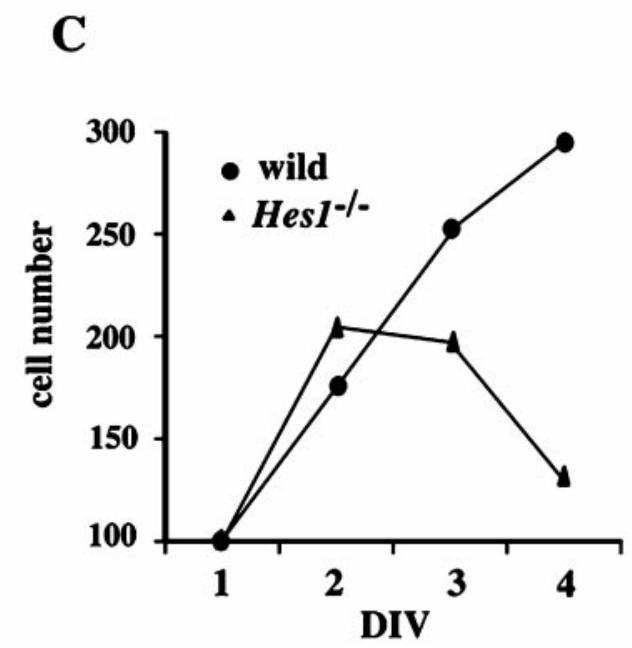

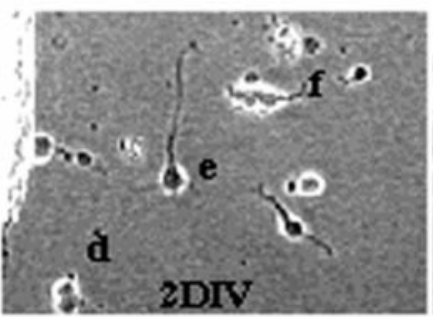
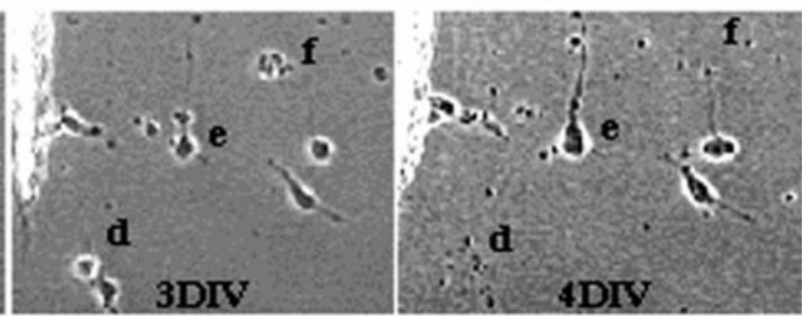

D

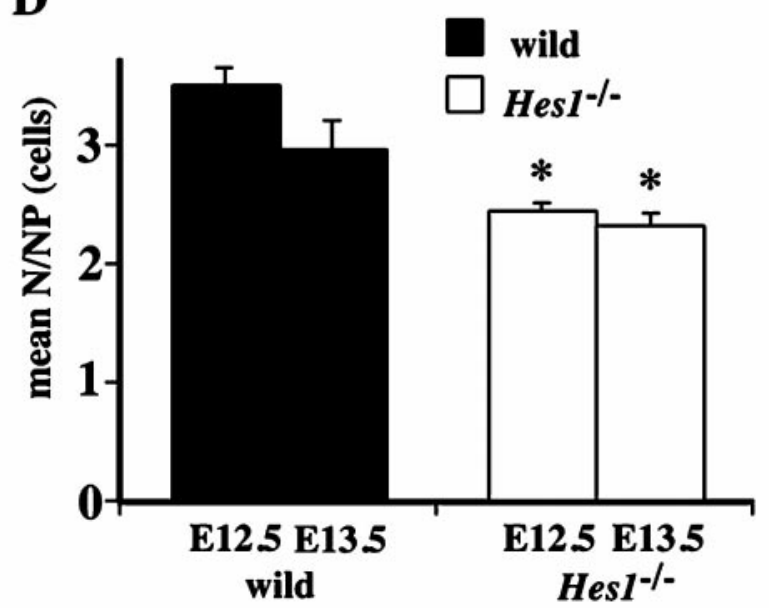

Figure 3. The developmental profiles of neuronal progenitor cells was followed in low-density culture. $A, B$, The dissociated cells derived from E13.5 telencephalons of wild-type $(A)$ and $H e s 1^{-1-}$ mice $\left(H e s 1^{-1-}, B\right)$, were clonally cultured, and phase-contrast photos of identical fields were obtained at $1,2,3$, and 4 DIV. The letters $a-f$ in each panel are placed beside the colony derived from the same single progenitor cell. For instance, in colony $b$ in the wild-type culture $(A)$, the single progenitor cell at 1 DIV underwent several cell divisions, and four cells were observed at 2 DIV. They extended their processes toward the neighboring colony a and appeared to form network-like connections by 3 DIV. This network of cells became better established, and cells showed a more differentiated neuronal morphology with long and branched processes by 4 DIV. These cells also appeared to keep dividing until 4 DIV. In contrast, in colonies $d$ and $f$ in the Hes $1^{-/-}$culture $(B)$, single progenitor cells divided once by 2 DIV, but the resulting cells soon fell into apoptosis ( $d$ at 4 DIV; $f$ at 3 DIV). The Hes $1^{-1-}$ neuron $e$ in $(B)$ extended thick processes rapidly by 2 DIV, but network-like connections were not formed as in the case of the wild-type culture at 4 DIV. $C$, Proliferating profiles of neuronal progenitor cells. The number of cells that originated from 100 neuronal progenitor cells in the low-density culture are summarized at the indicated day below the line graph. In the wild-type culture, progenitor cells kept increasing in number during the observation period. In contrast, the initial proliferation of progenitor cells was not disturbed by the Hes 1 mutation, but the cells stopped proliferating after 2 DIV and decreased in number (by apoptosis) in the Hes $1^{-/-}$culture. $D$, The average number of neurons derived from a single neuronal progenitor cell. Numbers of neurons are represented in each bar as the means \pm SEM of $\sim 100 \mathrm{NPs}$ of three independent experiments. ${ }^{*} p<0.05$ in comparison with the wild-type control of the same stage. The embryonic stages of the mice are indicated below each bar. The mean N/NP was reduced in $\mathrm{Hes}^{-1-}$ mice, irrespective of the developmental stage.

cephaly, suggesting accelerated apoptosis in the Hes1 ${ }^{-1-}$ brain (Ishibashi et al., 1995). To explore this possibility and investigate the cell types undergoing apoptosis, we examined the distribution of apoptotic cells in the brain. Figure $4 A-D$ shows TUNEL ${ }^{+}$ apoptotic cells, and their nuclear morphology is revealed by staining with Hoechst in the E10.5 brains. In the wild-type brains, dying cells were rare at E10.5, in agreement with previous observations (Blaschke et al., 1996). In contrast, there were TUNEL $^{+}$ apoptotic cells clustered near the ventricle in the E10.5 Hes ${ }^{-1-}$ brains. Figure $4 B$ shows one of the clusters of TUNEL ${ }^{+}$cells in the Hes ${ }^{-/-}$telencephalon. These $\mathrm{TUNEL}^{+}$cells appeared to be apoptotic rather than necrotic, based on the pyknotic nuclei (Fig. 4C,D). These apoptotic cells were likely to be neural progenitor cells and/or immature neurons, but not mature neurons, given their location (Bayer and Altman, 1991). This accelerated apoptosis was quantified by nuclear staining of dissociated telencephalic cells at 4 DIV (Fig. $4 E$ ). In the wild-type cultures, the fraction of apoptotic cells increased as neurogenesis progressed (from E10.5 to E14.5), consistent with the in vivo time course (Blaschke et al., 1996) (wild-type: E10.5 + 4 DIV, $12.8 \pm 4.3 \%$; E14.5 + 4 DIV, $36.9 \pm 2.8 \%)$. However, approximately half of the cultured $\mathrm{Hes}^{-/-}$cells underwent apoptosis $\left(\mathrm{Hes} \mathrm{I}^{-/-}\right.$: 
Figure 4. Accelerated apoptosis in the Hes $1^{-/-}$ brain. Apoptotic cells of an E10.5 brain were stained by the TUNEL method (green; DTAF) in wild-type (wild, A) and Hes $1^{-1-}\left(\right.$ Hes $\left.1^{-1-} ; B-D\right)$ mice. Clustered apoptotic cells were observed near the ventricle $(v l)$ in the Hes $1^{-1-}$ brain, whereas apoptotic cells were seldom detected in the wildtype brain. Two apoptotic cells $(B$, arrows) are also shown by TUNEL $(C)$ and Hoechst staining $(D)$, respectively. The TUNEL ${ }^{+}$cells $(C$, arrows) were also pyknotic $(D$, arrows), suggesting they were apoptotic rather than necrotic. Blue, nuclear staining with Hoechst; pia, pial side of the telencephalon. $E$, The fraction of apoptotic cells in vitro. The ratios of pyknotic (apoptotic) cells to total cells were determined by examining stained nuclei and presented as the means \pm SEM of at least three independent experiments. ${ }^{*} p<0.01$ in comparison with wild-type. The developmental stages of the embryos used are indicated below each bar. The apoptotic cells in the wild-type brain increased from E10.5 + 4 DIV to E14.5 + 4 DIV. In contrast, approximately half of the cells from the $H e s 1^{-1-}$ brain died within $4 \mathrm{DIV}$, independent of their original developmental stage. $F$, Apoptosis rescued with NT-3. Dissociated telencephalic cells from E12.5 wild-type (wild) and Hes $1^{-1-}$ $\left(\right.$ Hes $\left.1^{-1-}\right)$ mice were cultured for 4 DIV in defined medium (control). Twenty nanograms per milliliter NT-3 was added to this defined medium for assessing rescue from apoptosis by NT-3. The percentage of apoptotic cells in the telencephalic cultures was estimated at 4 DIV based on nuclear staining, and presented in each bar as the means \pm SEM of at least three independent experiments. ${ }^{*} p<0.01$ in comparison with wild-type or control. A large fraction of apoptotic cells was observed in the Hes $1^{-1-}$ cultures in the absence of NT-3 (control), which was markedly reduced by the administration of NT-3. In contrast, NT-3 had only a small effect on the level of apoptosis in the wild-type cultures.

Figure 5. A, Schematic model of neurogenesis in wild-type (wild) and Hes ${ }^{-/-}$mice (Hes $1^{-1-}$ ) based on the present results in vivo and in vitro. Because the Hes1 mutation relieves the repression of neuronal commitment by MPs, the selfrenewing capability of MPs is lowered (Fig. 2, represented as the thin circular arrow beside the Hes $1^{-1-}$ MPs in Fig. 5A), and the generation of NPs is increased (Table 1, more NPs are generated from $\mathrm{Hes} \mathrm{1}^{-1-}$ MPs in Fig. 5A). Prematurely committed, abnormal NPs become apoptotic $(* 1)$ or prematurely stop undergoing mitosis $(* 2)$ (accelerated apoptosis and a decreased number of daughter neurons from each NP; Figs. 3, 4). The increased number of neurons in early neurogenesis (before the lethal point of Hes $1^{-1-}$ mice around E14; transverse line in $A$ ) in Hes1 ${ }^{-1-}$ mice (Fig. 1) corresponds to the premature commitment and differentiation of cells in the neuronal lineage. Dotted lines encircle the representative lineage of single NPs based on the low-density culture experiments (Fig. 3). NPs of Hes $1^{-1-}$ mice are likely to have ceased mitosis prematurely. There are two possible mechanisms to explain this premature cessation: (1) the accelerated transition of the developmental stages from NP to N, and from MP to $\mathrm{NP}$, and (2) interruption of asymmetric cell division by the Hes 1 mutation. B, Diagrammatic representation of the regulation of neurogenesis by the Hes family. This diagram is based on the results of this and previous studies. Neurons $(N)$ are derived from multipotent progenitor cells $(M P)$; that is, a neural stem cell $(M P)$, directly or via an intermediate progenitor state, becomes a committed neuronal progenitor cell $(N P)$. Commitment and differentiation are two important, distinct steps in neurogenesis. Hes1 represses the commitment of MPs to the neuronal lineage, but not to glial lineages (*3; Table 1). Hes1 and Hes 5 repress neuronal differentiation in a redundant manner (*4; Figs. 1, 3; Ohtsuka et al., 1999).
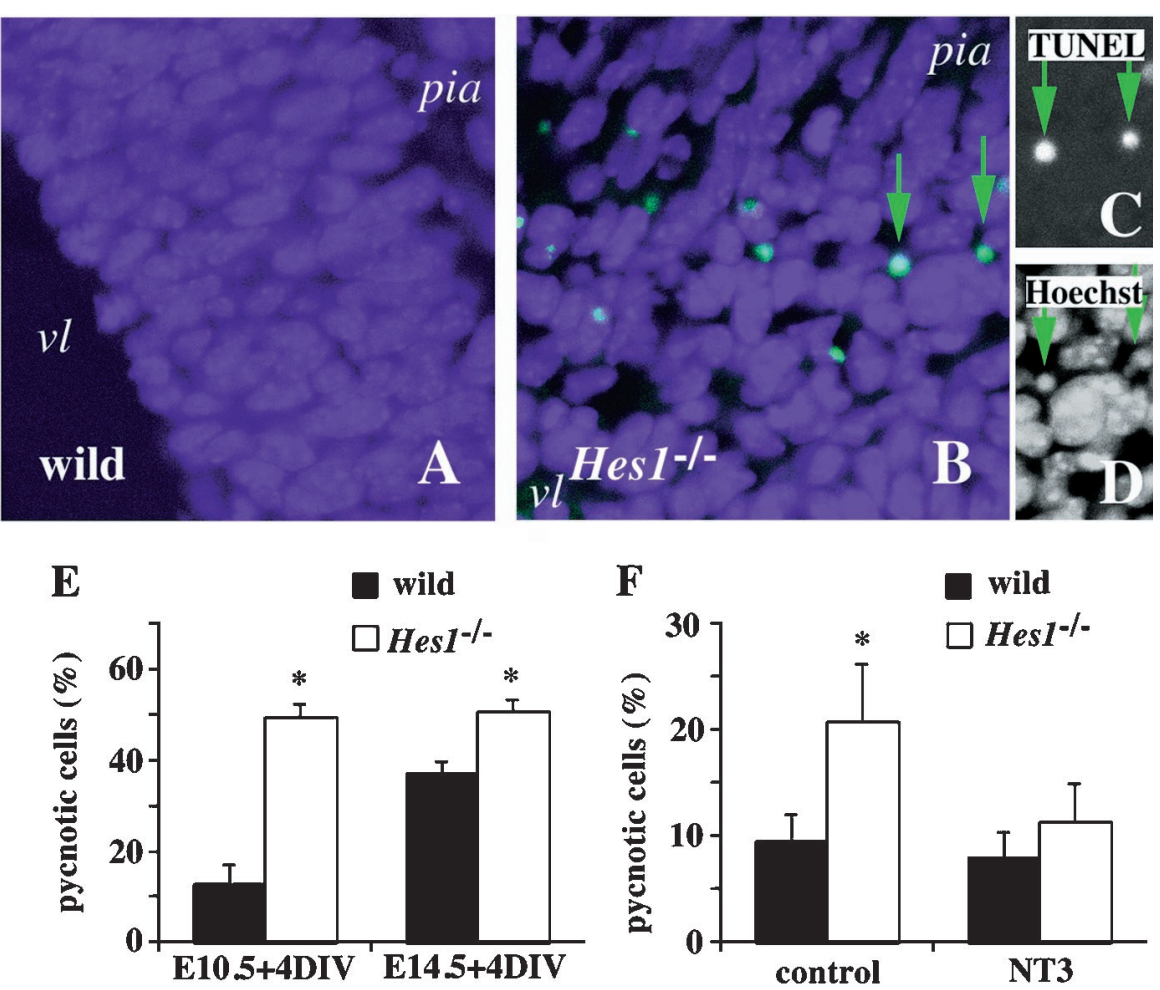

F

wild

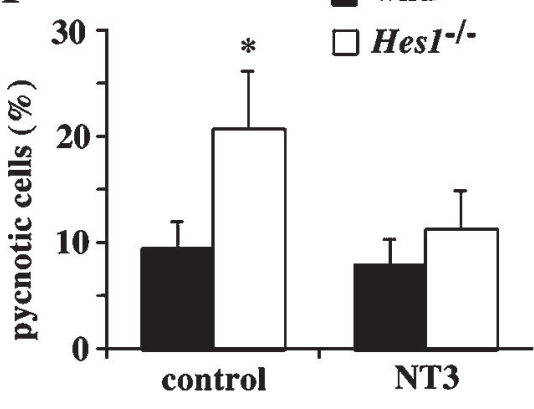

A

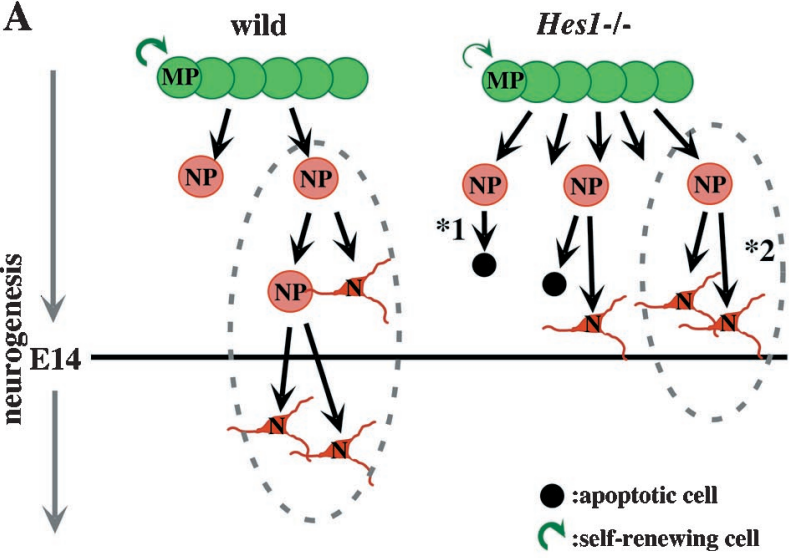

B

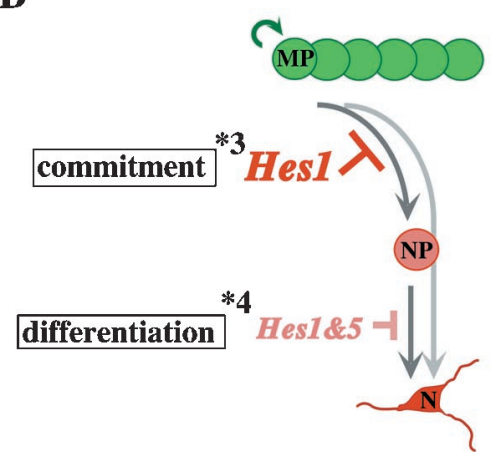


E10.5 + 4 DIV, $49.4 \pm 3.0 \% ; \mathrm{E} 14.5+4 \mathrm{DIV}, 50.8 \pm 2.4 \% ; * p<$ 0.01 compared to wild-type), independent of their original developmental stages.

To further investigate the cell types undergoing accelerated apoptosis in the Hes $1^{-/-}$brains, we examined the effects of neurotrophic factors on cultured cells. NT-3 is a neurotrophic factor that acts on mitotic neuronal progenitor cells to promote their withdrawal from the cell cycle (DiCicco-Bloom et al., 1993; Ghosh and Greenberg, 1995), rather than supporting the survival of postmitotic neurons (Ghosh and Greenberg, 1995). BDNF is thought to support the survival of mature neurons (Ghosh et al., 1994; Jones et al., 1994; Nawa et al., 1994; McAllister et al., 1995). Sister cultures were prepared from E12.5 Hes ${ }^{-1-}$ and wild-type telencephalons and cultured for 4 DIV in defined medium with or without one of the neurotrophic factors, then fixed and stained with Hoechst to estimate the ratio of apoptotic to total cells. In the absence of NT-3, the percentage of apoptotic cells in the Hes $1^{-1-}$ culture was approximately twice that in the wild-type culture (Fig. $4 F$ ) (wild-type, $9.4 \pm 1.6 \%$; Hes $1^{-1-}$, $20.7 \pm 5.3 \%$ ) $\left({ }^{*} p<0.01\right)$. Administration of NT-3 greatly reduced the percentage of apoptotic cells in the Hes $1^{-/-}$culture, whereas it had only a small effect on the level of apoptosis in the wild-type culture (Fig. 4F) (wild-type, $7.9 \pm 2.3 \%$; Hes $1^{-1-}, 11.2 \pm 3.6 \%$ ). Similar experiments were performed using BDNF, but a significant reduction of apoptotic cells was not seen for either Hes $1^{-/-}$or wild-type cultures (data not shown). Thus, it was suggested that NT-3-responsive NPs, which were abnormally committed to the neuronal lineage by the Hes 1 mutation, were undergoing apoptosis. However, it is also possible that some populations of immature neurons became apoptotic as a secondary effect of premature neuronal differentiation in the Hes $1^{-1-}$ brains.

Our present results can be summarized as follows (Fig. $5 A$ ). The Hes 1 mutation reduces the self-renewing ability of neural progenitor cells, and in turn accelerates the commitment of MPs to the neuronal lineage. The resultant NPs are increased in number, are functionally abnormal (i.e., they generate fewer daughter neurons, Fig. 3), and they follow an apoptotic fate.

\section{DISCUSSION}

\section{Neuronal determination, differentiation, or both?}

Neuronal development encompasses various events that occur throughout neuronal life, including the cell-fate decision (neuronal commitment), and postmitotic maturation (a narrow definition of neuronal differentiation). Hes 1 is expressed in the $\mathrm{VZ}$ at a high level (Sasai et al., 1992), and neurons are overproduced in the Hes $1^{-/-}$brain (Fig. 1A-H; Ohtsuka et al., 1999), raising the possibility that Hes 1 mainly represses commitment to the neuronal fate. However, because there was no evidence specifying the function of Hes 1 in neuronal commitment, the role of Hes 1 was identified-rather broadly — as a repressor of neuronal differentiation. To clarify the exact role of Hes1 in neuronal development, the cellular development of the Hes $1^{-/-}$brain was examined here in detail.

Hesl is known to negatively regulate neuronal differentiation: persistent expression of Hes 1 in neural progenitor cells in the VZ prevents expression of late neuronal markers (Ishibashi et al., 1994). The post-translational inhibition of Hes 1 is required for the neuronal differentiation of PC12 cells induced by NGF signaling (Ström et al., 1997). The present study demonstrated that the Hes $1^{-1-}$ immature neurons prematurely expressed late neuronal markers while they were still migrating (Fig. 1B,D, arrows). The low-density culture experiments demonstrated a quicker exten- sion of neuronal processes in Hes $1^{-1-}$ than in wild-type cultures (Fig. 3Be). Thus, the role of Hes 1 in negatively regulating neuronal differentiation (maturation) is well supported.

Furthermore, we showed in this paper that Hes 1 is necessary for neural progenitor cells to maintain their capacity for self-renewal and to repress the neuronal commitment of MPs, as follows.

First, we investigated whether or not Hes 1 plays its role in progenitor cells. TuJ1 and $\mathrm{Hu}$ are very early markers for postmitotic neurons that have just finished their final cell division (Lee et al., 1990; Menezes and Luskin, 1994; Sakakibara et al., 1996; Okano and Darnell, 1997; Wakamatsu and Weston, 1997), whereas MAP2 and neurofilament are late neuronal markers for postmigratory, mature neurons (Izant and McIntosh, 1980; Niinobe et al., 1988). Considering that even $\mathrm{TuJ} 1$ and $\mathrm{Hu}$ are prematurely expressed in vivo in the Hes $1^{-/-}$brain (Fig. $1 F, H$ ), it is most likely that the absence of Hes 1 affects the mitotic progenitor cells, (which do not express these markers), that is, MPs and/or NPs. In addition, the accelerated apoptosis that was observed near the ventricle in the Hes $1^{-1-}$ brain responded to NT-3, but not to BDNF, indicating that it was the NPs, rather than mature neurons, that underwent apoptosis. On the other hand, many mature $\mathrm{MAP}^{+}$neurons were observed in the Hes $1^{-1-}$ brain in vivo (Fig. $1 B, D$ ), and some Hes $1^{-1-}$ neurons in the low-density cultures survived beyond the observation period in vitro, as did wild-type neurons (Fig. 2A,B). Thus, mitotic progenitor cells (MPs and/or NPs), rather than mature neurons, are likely to be the target of Hesl action.

Second, our experiments using neurospheres, floating cell clusters derived from single sphere-producing cells (putative MPs) (Reynolds et al., 1992; Vescovi et al., 1993; Reynolds and Weiss, 1996), demonstrated that the self-renewing capability of Hes1 $1^{-/-}$ MPs is lower than that of wild-type MPs (Fig. 2). This weaker self-renewing activity indicates that the Hes 1 mutation converted the proliferation mode of MPs from self-renewal to non-selfrenewing. This conversion further suggests that Hes 1 acts on the MPs and maintains their capacity for self-renewal.

Finally, the neurosphere differentiation assay showed that Hes 1 functions to repress the neuronal commitment. The neurosphere differentiation assay is capable of discriminating, retrospectively, the multipotency and unipotency of the original sphere-producing cells. In wild-type mice, $>90 \%$ of the sphere-producing cells were multipotent, meaning they proliferate and differentiate into neurons and glia, and $<2 \%$ generated only neurons (Table 1). In Hes $1^{-1-}$ mice, however, $>20 \%$ of the sphere-producing cells generated only neurons, and $\sim 70 \%$ were multipotent. The increased number of neuronal clones in the sphere differentiation assays, together with the increased responsiveness of Hes $1^{-1-}$ cells to NT-3 (Fig. $4 F$ ), indicate that the number of NPs is increased in the Hes $1^{-1-}$ brain. These results suggest that Hes1 normally prevents the MPs from being committed to the neuronal lineage.

These observations strongly suggest that Hes1 functions to maintain the self-renewing state of MPs by repressing their commitment to the neuronal lineage. The premature differentiation of Hes $1^{-/-}$neurons might be a consequence of the accelerated neuronal commitment of the MPs, from which an increased number of abnormal NPs are generated in Hes $1^{-1-}$ mice. These points, together with the fact that Hes1 is normally expressed in the VZ, lead to the conclusion that Hes 1 mainly functions to repress neuronal commitment (Fig. 5B). However, our present experiments do not rule out the possibility that Hes 1 is involved in both neuronal commitment and differentiation at various steps in mammalian CNS development, as is another bHLH gene, 
NeuroD, in Xenopus (Lee et al., 1995) and murine retina (Morrow et al., 1999).

\section{Regulatory cascades in neurogenesis}

The negative bHLH transcription gene Hes 1 was originally identified as a mammalian homolog of hairy, which is a downstream target of the Drosophila Notch signaling pathway (Akazawa et al., 1992; Sasai et al., 1992). Here, our observations extend our knowledge of mammalian neurogenesis by examining the molecular basis of the action of Hes1.

It is known that the cascades of positive and negative bHLH transcription factors play important roles in mammalian neurogenesis (for review, see Kageyama et al., 1995; Lee, 1997). Recently, several groups proposed that Mash1, a positive bHLH gene, is required to specify intermediate progenitors (Lo et al., 1991; Casarosa et al, 1999; Torii et al., 1999). Mash1 mutant mice exhibit a severe loss of neuronal progenitor cells in the subventricular zone (Casarosa et al., 1999), and the onset of Mash1 expression coincides with the induction of differentiation (broad definition) of self-renewing stem cells in vitro (Torii et al., 1999). Considering that the transcription of Mash1 is negatively regulated by Hes 1, these proposals support our conclusion that Hes1 represses the first step of MP differentiation (neuronal commitment).

Notch signaling is known to be evolutionarily conserved, and Hes 1 appears to function as an effector gene of mammalian Notch signaling together with Hes5, in a redundant manner (Ohtsuka et al., 1999). Mammalian Notch signaling has pleiotropic functions. First, it negatively controls the rate at which stem cells differentiate, to avoid exhausting the stock of stem cells (ArtavanisTsakonas et al., 1995; Tanabe and Jessell, 1996). Second, the proper regulation of Notch signaling is also essential for asymmetric cell division (Guo et al., 1996; Jan and Jan, 1998). Third, activation of Notch signaling inhibits apoptosis (ArtavanisTsakonas et al., 1999). These functions of Notch signaling are consistent with our results. First, Hes ${ }^{-1-}$ MPs failed to maintain their self-renewing progenitor state and prematurely moved to the next developmental state (NP) (Fig. 2, Table 1). Second, the asymmetric cell division of the Hes $1^{-/-}$neural progenitor cells may be altered, resulting in two neurons, instead of one progenitor cell and one neuron in vitro (Figs. 3, 5A). Third, interrupted Notch signaling may have accelerated the apoptosis in the Hes $1^{-1-}$ brain (Fig. 4).

\section{The number of neurons}

The present study provided two seemingly inconsistent observations about the number of neurons: Hes $1^{-1-}$ neurons were overproduced in vivo (Fig. 1), whereas each of the Hes $1^{-/-}$NPs produced fewer neurons after $4 \mathrm{~d}$ in culture (reduced N/NP) (Fig. 3). These results can be interpreted as follows: In Hes $1^{-1-}$ mice, the increased number of NPs that results from the accelerated neuronal commitment of the MPs may dominate over the effects of the reduced number of progenitor divisions and of apoptosis, leading to an increase in the total number of neurons. The reduced number of N/NPs appeared to result from the Hes $1^{-1-}$ NPs becoming prematurely postmitotic, consistent with another aspect of the function of Hes1, in that alleviating the normal Hes 1 repression changes the developmental state of the neuronal lineage-from multipotent to unipotent (neuronal commitment), and from mitotic to postmitotic. Furthermore, the increased number of neurons in the Hes $1^{-1-}$ brain (before E14.5, Fig. $1 Q$ ) may correspond with only the earlier stage of neuronal generation, as represented in the first $2 \mathrm{~d}$ of low-density culture started at E12.5 or E13.5, because the mutant embryos die after E14 (Figs. 3, 5A). The simple model of neuronal lineage as seen in low-density culture is that the wild-type progenitor cell produces one selfrenewing progenitor cell and one postmitotic neuron, whereas the Hes $1^{-1-}$ progenitor cell generates two postmitotic neurons in the first $2 \mathrm{~d}$ in vitro (Fig. $5 A$ ). Thus, a greater number of Hes $1^{-/-}$than wild-type neurons were counted at the earlier stage of culture.

\section{Hes1 and gliogenesis}

Our observations suggest that Hes1 is not essential as a negative regulator of glial commitment (Table 1), at least in the telencephalon. However, persistent overexpression of Hes1 prevents the expression of both neuronal and glial markers in the mouse cortex (Ishibashi et al., 1994). The Hes $1^{-/-}$telencephalic cells in vitro started to express the glial marker GFAP slightly earlier than did the wild-type control (data not shown). Thus, it cannot be totally excluded that Hes1 negatively regulates glial differentiation, although Hes1 appeared not to be essential in repressing glial commitment in the mouse cortex. It is also possible that other members of the Hes family regulate glial development. For example, Hes5, not Hes1, is known to be involved in oligodendroglial differentiation (Wang et al., 1998).

\section{REFERENCES}

Akazawa C, Sasai Y, Nakanishi S, Kageyama R (1992) Molecular characterization of a rat negative regulator with a basic helix-loop-helix structure predominantly expressed in the developing nervous system. J Biol Chem 267:21879-21885.

Artavanis-Tsakonas S, Matsuno K, Fortini ME (1995) Notch signaling. Science 268:225-232.

Artavanis-Tsakonas S, Rand MD, Lake RJ (1999) Notch signaling: cell fate control and signal integration in development. Science 284:770-776.

Bayer SA, Altman J (1991) Neocortical development. New York: Raven.

Blaschke AJ, Staley K, Chun J (1996) Widespread programmed cell death in proliferative and postmitotic regions of the fetal cerebral cortex. Development 122:1165-1174.

Casarosa S, Fode C, Guillemot F (1999) Mash1 regulates neurogenesis in the ventral telencephalon. Development 126:525-534.

Cohen J, Wilkin GP (1995) Neural cell culture. New York: Oxford UP.

Crandall JE, Jacobson M, Kosik KS (1986) Ontogenesis of microtubuleassociated protein 2 (MAP2) in embryonic mouse cortex. Dev Brain Res 28:127-133.

Debus E, Weber K, Osborn M (1983) Monoclonal antibodies specific for glial fibrillary acidic (GFA) protein and for each of the neurofilament triplet polypeptides. Differentiation 25:193-203.

DiCicco-Bloom E, Friedman WJ, Black IB (1993) NT-3 stimulates sympathetic neuroblast proliferation by promoting precursor survival. Neuron 11:1101-1111.

Frederiksen K, McKay RD (1988) Proliferation and differentiation of rat neuroepithelial precursor cells in vivo. J Neurosci 8:1144-1151.

Galand P, Degraef C (1989) Cyclin/PCNA immunostaining as an alternative to tritiated thymidine pulse labeling for marking $\mathrm{S}$ phase cells in paraffin sections from animal and human tissues. Cell Tissue Kinet 22:383-392.

Gerdes J, Schwab U, Lemke H, Stein H (1983) Production of a mouse monoclonal antibody reactive with a human nuclear antigen associated with cell proliferation. Int J Cancer 31:13-20.

Ghosh A, Greenberg ME (1995) Distinct roles for bFGF and NT-3 in the regulation of cortical neurogenesis. Neuron 15:89-103.

Ghosh A, Carnahan J, Greenberg ME (1994) Requirement for BDNF in activity-dependent survival of cortical neurons. Science 263:1618-1623.

Guo M, Jan LY, Jan YN (1996) Control of daughter cell fates during asymmetric division: interaction of Numb and Notch. Neuron 17:27-41.

Guillemot F, Joyner AL (1993) Dynamic expression of the murine Achaete-scute homolog Mash1 in the developing nervous system. Mech Dev 42:171-185.

Hockfield S, McKay RD (1985) Identification of major cell classes in the developing mammalian nervous system. J Neurosci 5:3310-3328.

Hulspas R, Tiarks C, Reilly J, Hsieh CC, Recht L, Quesenberry PJ (1997) In vitro cell density-dependent clonal growth of EGF-responsive mu- 
rine neural progenitor cells under serum-free conditions. Exp Neurol 148:147-156.

Ingham PW, Howard KR, Ish-Horowicz D (1985) Transcription pattern of the Drosophila segmentation gene hairy. Nature 318:439-445.

Ishibashi M, Moriyoshi K, Sasai Y, Shiota K, Nakanishi S, Kageyama R (1994) Persistent expression of helix-loop-helix factor HES-1 prevents mammalian neural differentiation in the central nervous system. EMBO J 13:1799-1805.

Ishibashi M, Siew-Lan A, Shiota K, Nakanishi S, Kageyama R, Guillemot F (1995) Targeted disruption of mammalian hairy and Enhancer of split homolog-1 (HES-1) leads to up-regulation of neural helix-loophelix factors, premature neurogenesis, and severe neural tube defects. Genes Dev 9:3136-3148.

Izant JG, McIntosh JR (1980) Microtubule-associated proteins: a monoclonal antibody to MAP2 binds to differentiated neurons. Proc Natl Acad Sci USA 77:4741-4745.

Jan YN, Jan LY (1998) Asymmetric cell division. Nature 392:775-778.

Johnson GVW, Jope RS (1992) The role of microtubule-associated protein 2 (MAP2) in neuronal growth, plasticity, and degeneration. J Neurosci Res 33:505-512.

Johnson JE, Birren SJ, Anderson DJ (1990) Two rat homologues of Drosophila achaete-scute specifically expressed in neuronal precursors. Nature 346:858-861.

Jones KR, Farinas I, Backus C, Reichardt LF (1994) Targeted disruption of the BDNF gene perturbs brain and sensory neuron development but not motor neuron development. Cell 76:989-999.

Kageyama R, Nakanishi S (1997) Helix-loop-helix factors in growth and differentiation of the vertebrate nervous system. Curr Opin Genet Dev 7:659-665.

Kageyama R, Sasai Y, Akazawa C, Ishibashi M, Takebayashi K, Shimizu C, Tomita K, Nakanishi S (1995) Regulation of mammalian neural development by helix-loop-helix transcription factors. Crit Rev Neurobiol 9:177-188.

Kaneko Y, Sakakibara S, Imai T, Suzuki A, Nakamura Y, Sawamoto K, Ogawa Y, Toyama Y, Miyata T, Okano H (2000) Musashi1: an evolutionally conserved marker for CNS progenitor cells including neural stem cells. Dev Neurosci 22:138-152.

Klämbt C, Knust E, Tietze K, Campos-Ortega JA (1989) Closely related transcripts encoded by the neurogenic gene complex Enhancer of split of Drosophila melanogaster. EMBO J 8:203-210.

Lee JE (1997) Basic helix-loop-helix genes in neural development. Curr Opin Neurobiol 7:13-20.

Lee JE, Hollenberg SM, Snider L, Turner D, Lipnick N, Weintraub H (1995) Conservation of Xenopus Ectoderm into neurons by NeuroD, a basic helix-loop-helix protein. Science 268:836-844.

Lee MK, Tittle JB, Rebhun LI, Cleveland DW, Frankfurter A (1990) The expression and posttranslational modification of a neuron-specific $\beta$-tubulin isotype during chick embryogenesis. Cell Motil Cytoskel 17:117-132.

Lendahl U, Zimmerman LB, McKay RDG (1990) CNS stem cells express a new class of intermediate filament protein. Cell 60:585-595.

Lillien L (1998) Neural progenitors and stem cells: mechanisms of progenitor heterogeneity. Curr Opin Neurobiol 8:37-44.

Lo LC, Johnson JE, Wuenschell CW, Saito T, Anderson DJ (1991) Mammalian achaete-scute homolog 1 is transiently expressed by spatially-restricted subsets of early neuroepithelial and neural crest cells. Genes Dev 5:1524-1537.

Luskin MB, Pearlman AL, Sanes JR (1988) Cell lineage in the cerebral cortex of the mouse studied in vivo and in vitro with a recombinant retrovirus. Neuron 1:635-647.

Marusich MF, Furneasx HM, Henion PD, Weston JA (1994) Hu neuronal proteins are expressed in proliferating neurogenic cells. J Neurobiol 25:143-155.

Mayer-Proschel M, Kalyani AJ, Mujtaba T, Rao MS (1997) Isolation of lineage-restricted neuronal precursors from multipotent neuroepithelial stem cells. Neuron 19:773-785.

McAllister AK, Lo DC, Kats LC (1995) Neurotrophins regulate dendritic growth in developing visual cortex. Neuron 15:791-803.

McConnell SK (1995) Constructing the cerebral cortex: neurogenesis and fate determination. Neuron 15:761-768.

Menezes JR, Luskin MB (1994) Expression of neuron-specific tubulin defines a novel population in the proliferative layers of the developing telencephalon. J Neurosci 14:5399-5416.

Miyata T, Ogawa M (1994) Developmental potentials of early telence- phalic neuroepithelial cells: a study with microexplant culture. Dev Growth Differ 36:319-331.

Morrow EM, Furukawa T, Lee JE, Cepko CL (1999) NeuroD regulates multiple functions in the developing neural retina in rodent. Development 126:23-36.

Nakao K, Campos-Ortega JA (1996) Persistent expression of genes of the Enhancer of Split complex suppresses neural development in Drosophila. Neuron 16:275-286.

Nawa H, Pelleymounter MA, Carnahan J (1994) Intraventricular administration of BDNF increases neuropeptide expression in newborn rat brain. J Neurosci 14:3751-3765.

Niinobe M, Maeda N, Ino H, Mikoshiba K (1988) Characterization of microtubule-associated protein 2 from mouse brain and its localization in the cerebellar cortex. J Neurochem 51:1132-1139.

Ohtsuka T, Ishibashi M, Gradwohl G, Nakanishi S, Guillemot F, Kageyama R (1999) Hes1 and Hes5 as Notch effectors in mammalian neuronal differentiation. EMBO J 18:2196-2207.

Okano HJ, Darnell RB (1997) A hierarchy of Hu RNA binding proteins in developing and adult neurons. J Neurosci 17:3024-3037.

Qian X, Goderie SK, Shen Q, Stern JH, Temple S (1998) Intrinsic programs of patterned cell lineages in isolated vertebrate CNS ventricular zone cells. Development 125:3143-3152.

Rakic P (1988) Specification of cerebral cortical areas. Science 241:170-176.

Reynolds BA, Weiss S (1996) Clonal and population analyses demonstrate that an EGF-responsive mammalian embryonic CNS precursor is a stem cell. Dev Biol 175:1-13.

Reynolds BA, Tetzlaff W, Weiss S (1992) A multipotent EGFresponsive striatal embryonic progenitor cell produces neurons and astrocytes. J Neurosci 12:4565-4574.

Sakakibara S, Okano H (1997) Expression of neural RNA-binding proteins in the postnatal CNS: implications of their roles in neuronal and glial cell development. J Neurosci 17:8300-8312.

Sakakibara S, Imai T, Hamaguchi K, Okabe M, Aruga J, Nakajima K, Yasutomi D, Nagata T, Kurihara Y, Uesugi S, Miyata T, Ogawa M, Mikoshiba K, Okano H (1996) Mouse-Musashi-1, a neural RNAbinding protein highly enriched in the mammalian CNS stem cell. Dev Biol 176:230-242.

Sasai Y, Kageyama R, Tagawa Y, Shigemoto R, Nakanishi S (1992) Two mammalian helix-loop-helix factors structurally related to Drosophila hairy and Enhancer of split. Genes Dev 6:2620-2634.

Schlüter C, Duchrow M, Wohlenberg C, Becker MHG, Key G, Flad HD, Gerdes J (1993) The cell proliferation-associated antigen of antibody Ki-67: a very large, ubiquitous nuclear protein with numerous repeated elements, representing a new kind of cell cycle-maintaining proteins. J Cell Biol 123:513-522.

Ström A, Castella P, Rockwood J, Wagner J, Caudy M (1997) Mediation of NGF signaling by post-translational inhibition of HES-1, a basic helix-loop-helix repressor of neuronal differentiation. Genes Dev 11:3168-3181.

Takebayashi K, Sasai Y, Sakai Y, Watanabe T, Nakanishi S, Kageyama R (1994) Structure, chromosomal locus, and promoter analysis of the gene encoding the mouse helix-loop-helix factor HES1: negative autoregulation through the multiple $\mathrm{N}$ box elements. J Biol Chem 269:5150-5156.

Tanabe Y, Jessell TM (1996) Diversity and pattern in the developing spinal cord. Science 274:1115-1123.

Temple S (1989) Division and differentiation of isolated CNS blast cells in microculture. Nature 340:471-473.

Thomson JA, Marshall VS, Trojanowski JQ (1998) Neural differentiation of rhesus embryonic stem cells. APMIS 106:149-157.

Torii M, Matsuzaki F, Osumi N, Kaibuchi K, Nakamura S, Casarosa S, Guillemot F, Nakafuku M (1999) Transcription factors Mash-1 and Prox-1 delineate early steps in differentiation of neural stem cells in the developing central nervous system. Development 126:443-456.

Tropepe V, Sibilia M, Ciruna BG, Rossant J, Wagner EF, van der Kooy D (1999) Distinct neural stem cells proliferate in response to EGF and FGF in the developing mouse telencephalon. Dev Biol 208:166-188.

Vescovi AL, Reynolds BA, Fraser DD, Weiss S (1993) bFGF regulates the proliferative fate of unipotent (neuronal) and bipotent (neuronal/ astroglial) EGF-generated CNS progenitor cells. Neuron 11:951-966.

Wakamatsu Y, Weston JA (1997) Sequential expression and role of Hu RNA-binding proteins during neurogenesis. Development 124:3449-3460.

Wang S, Sdrulla AD, duSibio G, Bush G, Nofziger D, Hicks C, Weinmaster G, Barres BA (1998) Notch recepter activation inhibits oligodendrocyte differentiation. Neuron 21:63-75. 